\title{
Pattern of growth of dominant follicles during the oestrous cycle of heifers
}

\author{
J. D. Savio, L. Keenan, M. P. Boland* and J. F. Roche \\ Faculty of Veterinary Medicine, University College Dublin, Ballsbridge, Dublin 4, Ireland and \\ *Faculty of Agriculture, University College Dublin, Lyons Estate, Newcastle, Co. Dublin, Ireland
}

\begin{abstract}
Summary. Ovarian follicular development was studied in 13 heifers by daily ultrasound examination during 2 complete and consecutive natural oestrous cycles. In 21 cycles $(81 \%) 3$ dominant follicles were identified, in 4 cycles $(15 \%) 2$ and in the remaining cycle $1(4 \%)$. Consistently, the first dominant follicle was detected on average on Day 4 , reached a maximum size on Day 6 , went through a period of relative stability between Days 6 and 10, then began to decrease in size and was undetectable by Day 15 . The second dominant follicle was detected by Day 12, reached maximum size on Day 16 (or 19 in the 4 cycles in which the 2 nd dominant follicle was the ovulatory follicle) and was undetectable by Day 19. The 3rd (ovulatory) follicle was identified on average by Day 16 (range Days 10 to 19 ) and maximum size was reached on Day 21. The ovulatory follicles were larger $(P<0.05)$ than the previous ones and the stage of the cycle at which maximum size was reached was significantly different for each dominant follicle $(P<0.05)$. The analysis of the rates of growth and atresia suggest that the rate of growth is slowest during mid-cycle. The number of dominant follicles that developed in the ovary ipsilateral to the corpus luteum was greater $(P<0.05)$ than in the contralateral ovary.
\end{abstract}

Keywords: heifer; dominant follicle; growth; oestrous cycle; ultrasound

\section{Introduction}

The physiological control of recruitment, selection, growth, dominance, and atresia of ovarian follicles in livestock is not clearly understood. Since Rajakoski (1960) reported two 'waves' of follicular growth during the oestrous cycle of cattle, one between Days 3 and 12 and the other between Day 12 and the subsequent oestrus, numerous studies have been carried out to assess the dynamics of follicular development. Donaldson \& Hansel (1968) reported that growth and atresia of ovarian follicles appeared to be a continuous process, and no distinct mid-cycle waves in follicular growth were identified. Matton et al. (1981) indicated that the growth and replacement of large follicles was more rapid at the end than at the beginning of the oestrous cycle. They reported that there were periods of growth of follicles between Days 3 and 13, Days 13 and 18 and Days 18 and oestrus. Ireland \& Roche (1983) found that at least two periods of growth and atresia occur in heifers before Day 13, one between Days 3 and 7 and the other between Days 7 and 13. Subsequently, Ireland \& Roche (1987) suggested, based on the changes of concentrations of oestradiol in ovarian venous blood, that at least three periods of follicular growth occur during the oestrous cycle.

Until recently, studies of ovarian follicular dynamics were limited to observations of ovaries at slaughter, ovariectomy, or surgery by marking follicles with India ink. These findings were limited either to a single observation in time on each animal or to a limited number of observations in the same animal at surgery. Therefore, as most observations represented only one point in time in a 
single animal, it is difficult to obtain an accurate picture of the dynamics of follicular growth and regression throughout a complete oestrous cycle. Ultrasonography has proved to be an effective means of monitoring and evaluating ovarian follicles in cattle (Pierson \& Ginther, 1984; Quirk et al., 1986), but sequential changes in the sizes of individual follicles during a complete oestrous cycle have not been reported. The objective of this present experiment was to study morphologically changes in patterns of growth and disappearance of dominant follicles in heifers during the oestrous cycle, by daily ultrasonic scanning.

\section{Materials and Methods}

\section{Ovarian examination}

The ovaries of 13 Friesian $\times$ Hereford cyclic beef heifers, weighing $380-500 \mathrm{~kg}$, were examined by ultrasonography for at least 2 normal oestrous cycles (day of oestrus = Day 0 ). The ultrasound machine used was a system XLP linear array real-time, ultrasound scanner, with a 5-MHz transducer probe (Dynamic Imaging Ltd, Livingston EH54 9BX, U.K.). All examinations were done daily by the same operator. Faecal material was removed from the rectum before examination. Each ovary was separately located and the transducer inserted per rectum and moved over the surface of the ovary. When necessary, the image was frozen on the screen and the size of the follicle measured. After each examination, diagrams of the relative positions of the follicles and relationship to other ovarian structures were drawn, allowing individual follicles to be identified on successive days. When the image of the follicle being scanned was not spherical, the diameter was estimated by averaging the longest and shortest diameters.

To relate follicular dynamics to blood concentrations of progesterone, the ovaries of two cyclic post-partum cows were scanned and they were bled daily for progesterone analysis. Plasma concentrations of progesterone were determined by radioimmunoassay (Dieleman \& Schoenmakers, 1979). The intra- and interassay coefficients of variation were $2 \%$ and $12 \%$ respectively. The sensitivity of the assay was $0.1 \mathrm{ng} / \mathrm{ml}$.

\section{Definitions used}

Day of maximum diameter: the day at which the maximum diameter was obtained. When a follicle had the same diameter for more than 1 day, the first day was taken as the day of maximum diameter.

Maximum size: the largest diameter obtained.

Duration of growth: the number of days between the first measurement of the follicle and its maximum size plus 1 day ( 1 day was added to take account of a plateau in growth rate).

Growth rate: the maximum size divided by the duration of growth.

Duration of atresia: the number of days between the day of maximum diameter and the last observation of each follicle plus 1 day.

Rate of atresia: the maximum size divided by duration of atresia.

Duration of detection: the sum of duration of growth and atresia of each follicle.

Dominant follicle: those follicles that were the largest during a given period of time.

Secondary follicles: those follicles that grew during periods of time when dominant follicles were present.

\section{Statistical analysis}

The following transformations of the data were made to normalize error distributions and to stabilize treatment variances: (1) $\log$, for day of maximum diameter, maximum size, duration of atresia and duration of detection; and (2) square root for growth rate, duration of growth and rate of atresia. Since non-random repeat measurements on the same animal were used, data from cycles with 3 dominant follicles were analysed as a split plot model after testing for homogeneity of variance and covariance using the sphericity test (Anderson, 1958). Heifers were considered as replicates, each cycle as a main plot and each follicle within a cycle as a sub plot (Gill, 1978). The general linear model procedure of the Statistical Analysis System (SAS, 1986) was used. Differences between follicles were tested using Tukey's Multiple Comparisons Test. Data from cycles with 2 dominant follicles $(4$ cycles) were analysed using two-sample or paired $t$ tests to compare means.

For the purpose of plotting the data on the pattern of growth of the dominant follicles (Figs 2a and 2b), the mean day of maximum diameter of the dominant follicle was obtained, and the data were centralized around this day. When proportions were considered, a test of significance of binomial proportions (Snedecor \& Cochran, 1980) was applied to test the null hypothesis that it was 0.50 at the $5 \%$ level of significance. A paired $t$ test was used to compare number of follicles. 


\section{Validation of the ultrasound data}

The ovaries of 12 heifers and 4 cows were examined by ultrasound before slaughter. The reproductive tracts were obtained the same day and the follicles present were measured with calipers. Of 52 follicles identified by ultrasound, 51 $(98 \%)$ had the same position at slaughter. In one case, two adjacent small follicles were wrongly diagnosed by ultrasound as one medium-sized follicle. The overall correlation coefficient between ultrasound and manual caliper measurements was $0 \cdot 87$. When the follicles were classified based on diameter, into two classes, small ( $\leq 9 \mathrm{~mm})$ and large $(\geq 10 \mathrm{~mm})$, the respective correlation coefficients were 0.86 and 0.72 .

\section{Results}

The mean length ( \pm standard deviation, s.d.) of the 26 oestrous cycles studied was $21 \cdot 1 \pm 1 \cdot 5$ days with a range of 19-25 days. In 21 cycles $(81 \%), 3$ dominant follicles were identified, in 4 cycles $(15 \%) 2$ were identified and in the remaining cycle $(4 \%)$, there was only 1 dominant follicle. The 5 cycles without 3 dominant follicles were not repeated within the same animal. In $50 \%$ of the cycles, the growth of a secondary follicle with a diameter $>10 \mathrm{~mm}$ occurred (see Fig. 4, Heifers 752 and 742).

The development of dominant follicles in relation to the position of the corpus luteum (CL) was examined. Of 72 dominant follicles detected, 45 developed in the ovary ipsilateral to the $\mathrm{CL}$ $(P<0.05)$. In 17 of 25 cycles, the first and second dominant follicles developed in the same ovary $(P=0 \cdot 12)$. In 14 of 21 cycles the third dominant follicle developed on the side opposite to the second dominant follicle $(P=0.09)$.

The follicular population located in the region of the ovary where the image was frozen was recorded. The daily mean numbers of small $(\leq 4 \mathrm{~mm})$, medium $(5-9 \mathrm{~mm})$ and large $(\geq 10 \mathrm{~mm})$ follicles are shown in Fig. 1. The numbers of medium and large follicles varied from 1 to 2 during most days of the oestrous cycle, except at the beginning of the cycle when the number of follicles in these classes was less than 1 . In contrast, the number of small follicles detected was constant during the major part of the cycle but decreased significantly towards the end. The average number of small follicles on Days 16, 17, 18, 19 and 20 was smaller than on Days 1, 2, 3, 4 and $5(P<0 \cdot 05)$.

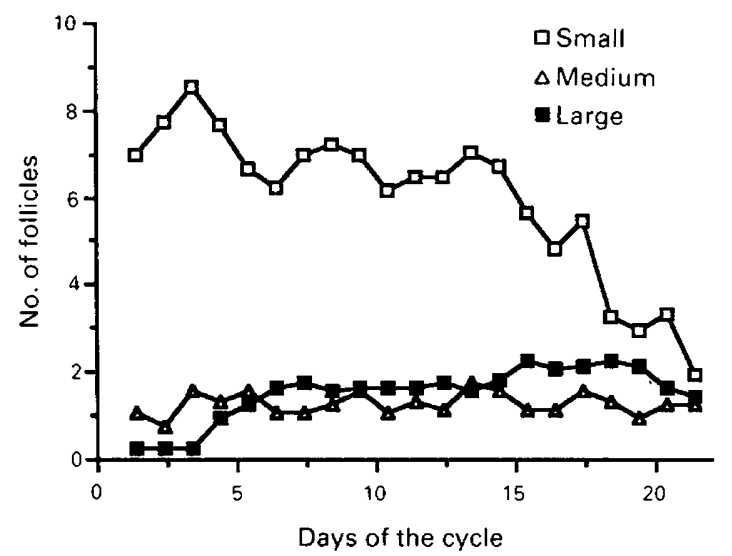

Fig. 1. Mean number of small, medium and large follicles detected by ultrasound during the oestrous cycle in heifers.

\section{Cycles with 3 dominant follicles}

The mean length of cycles with 3 dominant follicles (Fig. 2a) was $21.3 \pm 1.5$ days. The first dominant follicle was identified, on average, by Day 4 (range Days 2-5), reached its maximum size by Day 6 and was detectable on average until Day 15 (range Days 10-20). After rapid growth 


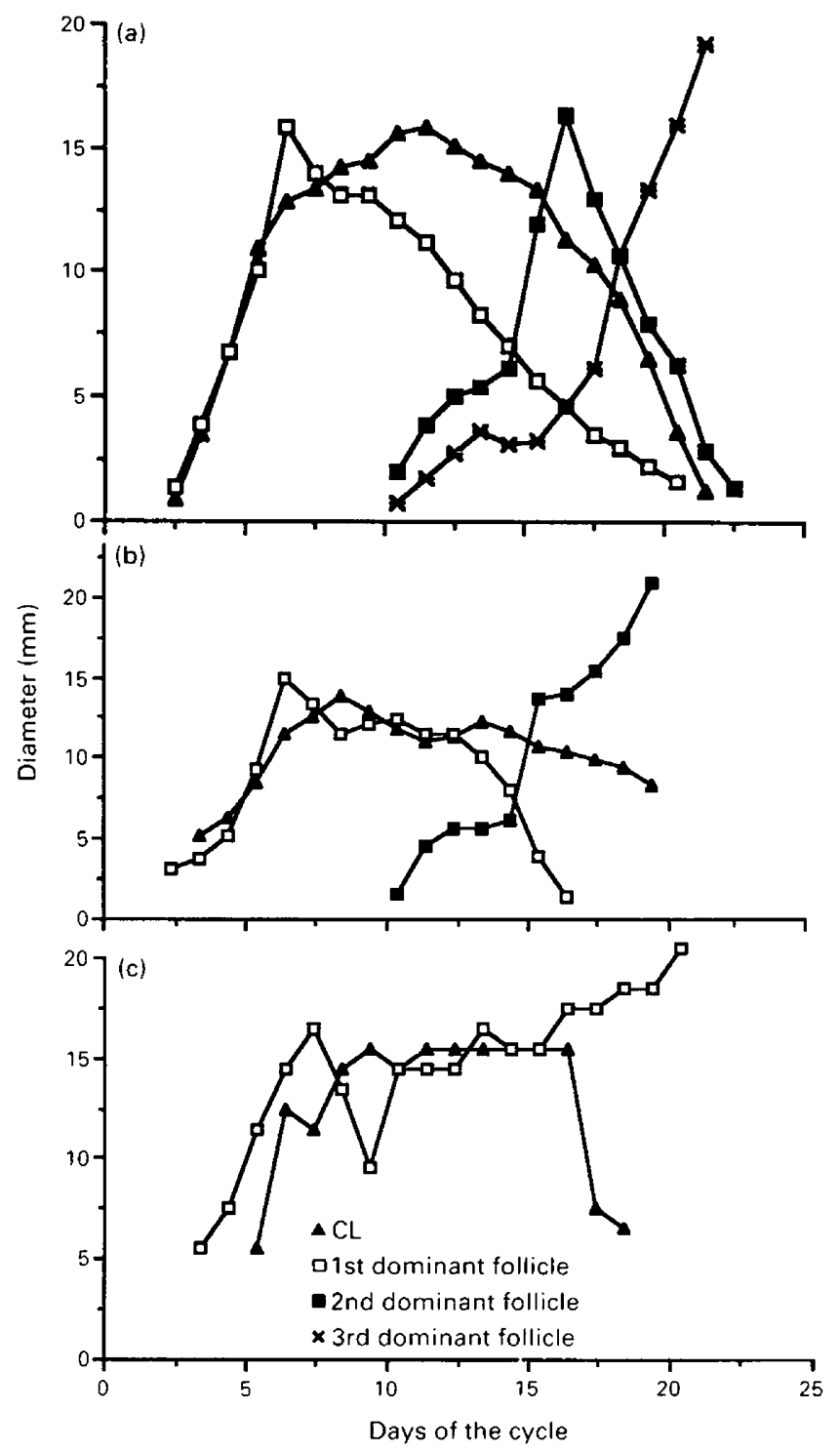

Fig. 2. Growth pattern of the dominant follicle during the oestrous cycle of heifers with (a) 3 dominant follicles, (b) 2 dominant follicles, and (c) only 1 dominant follicle.

between Days 4 and 6, the size of the first dominant follicle remained stable between Days 6 and 10 . The peak size observed in some heifers by Days 9-10 (Fig. 2a) was due to some dominant follicles either reaching maximum diameter at this time (Fig. 4, Heifers 872 and 742) or to a second peak in the size of other dominant follicles (Fig. 4, Heifer 752 and 722). After Day 10, there was a marked decrease in size of the first dominant follicle which was highly variable between cycles. On average, the first dominant follicle was undetectable by Day 15 (range Days 10-20).

The second dominant follicle was present on average between Days 12 and 19 (range Days 10-22) and reached maximum size on Day 16 (range Days 13-18) (Fig. 2a). Finally, the third dominant follicle, which ovulated, was detected, on average, by Day 16 (range Days 10-19) and, 
Table 1. Various follicular characteristics measured during oestrous cycles in which 2 or 3 dominant follicles were detected, after daily examination of the ovaries of heifers by ultrasound

\begin{tabular}{|c|c|c|c|c|c|c|c|}
\hline Follicle & $\begin{array}{l}\text { Growth } \\
\text { rate } \\
\text { (mm/day) }\end{array}$ & $\begin{array}{l}\text { Duration } \\
\text { of } \\
\text { growth } \\
\text { (days) }\end{array}$ & $\begin{array}{l}\text { Duration of } \\
\text { detection } \\
\text { of dominant } \\
\text { follicles } \\
\text { (days) }\end{array}$ & $\begin{array}{c}\text { Maximum } \\
\text { size } \\
(\mathrm{mm})\end{array}$ & $\begin{array}{c}\text { Day of } \\
\text { maximum } \\
\text { diameter }\end{array}$ & $\begin{array}{l}\text { Rate of } \\
\text { atresia } \\
\text { (mm/day) }\end{array}$ & $\begin{array}{c}\text { Duration } \\
\text { of } \\
\text { atresia } \\
\text { (days) }\end{array}$ \\
\hline \multicolumn{8}{|c|}{ Heifers with 3 dominant follicles $(\mathrm{N}=21)$} \\
\hline First & $\begin{array}{c}5.49 \pm \\
0.79^{\mathrm{a}}\end{array}$ & $\begin{array}{c}3 \cdot 35 \pm \\
0.25^{\mathrm{a}}\end{array}$ & $\begin{array}{c}11.35 \pm \\
0.86^{\mathrm{a}}\end{array}$ & $\begin{array}{c}15.45 \pm \\
0.52^{\mathrm{a}}\end{array}$ & $\begin{array}{c}6 \cdot 30 \pm \\
0 \cdot 23^{\mathrm{a}}\end{array}$ & $\begin{array}{c}1.87 \pm \\
0.23^{\mathrm{a}}\end{array}$ & $\begin{array}{c}10 \cdot 00 \pm \\
0.89^{\mathrm{a}}\end{array}$ \\
\hline Second & $\begin{array}{c}4 \cdot 30 \pm \\
0.52^{\mathrm{ab}}\end{array}$ & $\begin{array}{c}4 \cdot 75 \pm \\
0.60^{\mathrm{ab}}\end{array}$ & $\begin{array}{l}7.35 \pm \\
0.85^{\mathrm{b}}\end{array}$ & $\begin{array}{c}15.90 \pm \\
0.51^{\mathrm{a}}\end{array}$ & $\begin{array}{l}5 \cdot 70 \pm \\
0.53^{\mathrm{b}}\end{array}$ & $\begin{array}{c}3 \cdot 90 \pm \\
0.38^{\mathrm{b}}\end{array}$ & $\begin{array}{c}4 \cdot 60 \pm \\
0.34^{\mathrm{b}}\end{array}$ \\
\hline Third & $\begin{array}{c}3 \cdot 61 \pm \\
0.39^{\mathrm{b}}\end{array}$ & $\begin{array}{r}6 \cdot 31 \pm \\
0.69^{b}\end{array}$ & $\begin{array}{c}6 \cdot 10 \pm \\
0 \cdot 72^{\mathrm{b}}\end{array}$ & $\begin{array}{c}18.63 \pm \\
0.83^{5}\end{array}$ & $\begin{array}{r}21 \cdot 00 \pm \\
0.37^{c}\end{array}$ & & \\
\hline \multicolumn{8}{|c|}{ Heifers with 2 dominant follicles $(\mathrm{N}=4)$} \\
\hline First & $\begin{array}{c}4.75 \pm \\
1.03^{2}\end{array}$ & $\begin{array}{c}3.50 \pm \\
0.87^{\mathrm{a}}\end{array}$ & $\begin{array}{c}14 \cdot 25 \pm \\
2 \cdot 86^{\mathrm{a}}\end{array}$ & $\begin{array}{c}14 \cdot 25 \pm \\
0.48^{\mathrm{a}}\end{array}$ & $\begin{array}{l}6.00 \pm \\
0.58^{\mathrm{a}}\end{array}$ & & \\
\hline Second & $\begin{array}{r}2.95 \pm \\
2.55^{\mathrm{a}}\end{array}$ & $\begin{array}{c}7 \cdot 50 \pm \\
1 \cdot 19^{\mathrm{b}}\end{array}$ & $\begin{array}{c}9.00 \pm \\
1.08^{\mathrm{a}}\end{array}$ & $\begin{array}{c}20.25 \pm \\
0.75^{b}\end{array}$ & $\begin{array}{c}19 \cdot 25 \pm \\
0.25^{\mathrm{b}}\end{array}$ & & \\
\hline
\end{tabular}

Values are mean \pm s.e.m.

Values with different superscripts differ $(P<0.05)$.

after a period of slow growth up to Day 17 , growth rate increased and this follicle reached maximum diameter on Day 21 (range Days 19-24), the mean day before ovulation occurred (Fig. 2a). The coefficient of variation (CV) of transformed parameters for temporal measurements, e.g. day of maximum diameter or day of maximum size, ranged from 5.3 to $5.5 \%$, whereas $\mathrm{CV}$ for transformed parameters relating to dynamic events, e.g. duration and rates of follicular growth and atresia and duration of detection, were larger and ranged from 16.5 to $25 \cdot 3 \%$.

Day of maximum diameter. The mean days of maximum diameter for the 3 dominant follicles were 6,16 and 21 (Table 1), and differences between the 3 days were significant $(P<0.05)$.

Maximum size. The maximum size of the dominant follicles was, on average, 15.5, 15.9 and $18.8 \mathrm{~mm}$ for the 1st, 2nd and 3rd dominant follicle respectively. The ovulatory follicle was significantly larger $(P<0.05)$ than the first and second dominant follicles (Table 1$)$.

Growth rate. Growth rate was not linear each day (Fig. 2a) but the mean growth rates per day were $5 \cdot 5,4 \cdot 3$ and $3.6 \mathrm{~mm}$ respectively for the 3 dominant follicles. Significant differences $(P<0.05)$ were detected only between follicles 1 and 3 .

Duration of growth. The mean duration of growth for each follicle was: $3 \cdot 4,4 \cdot 8$ and $6 \cdot 3$ days for dominant follicles 1,2 and 3 (Table 1), and follicles 1 and 3 had statistically different $(P<0.05)$ durations of growth.

Atresia rate. The mean rates of atresia for the 1 st and 2 nd dominant follicles were 1.9 and $3.9 \mathrm{~mm}$ per day (Table 1$)(P<0.05)$.

Length of atresia. The mean lengths of atresia were 10 and $4 \cdot 6$ days for the 1 st and 2 nd follicles $(P<0.05)$.

Duration of detection. The mean durations of detection for the 1st, 2nd and 3rd dominant follicles were $11.4,7.4$ and 6.1 days. The mean duration of detection for the 1 st follicle was significantly longer $(P<0.05)$ than those for the 2 nd and 3rd dominant follicles, but there was no difference in duration of detection between the last two.

\section{Cycles with two dominant follicles}

The mean length of the cycles in heifers having two dominant follicles was $20.5 \pm 1.3$ days, which was not different from that for cycles with 3 dominant follicles. The 1st dominant follicle was 
identified between Days 3 and 4, and reached maximum diameter on Day 6; after a period of stability in size between Days 6 and 12, the diameter decreased and this follicle was not detectable, on average, by Day 15. The 2nd dominant follicle, which ovulated, was identified on average on Day 10, and reached maximum diameter on Day 19 (Fig. 2b). Comparing the 1st and 2nd dominant follicles, growth rate and duration of detection were not different (Table 1) but duration of growth, maximum size obtained and day of maximum diameter were significantly different $(P<0 \cdot 05)$.

\section{Cycle with one dominant follicle}

One oestrous cycle in a heifer with only one dominant follicle was identified and the duration of this cycle was 19 days (Fig. 2c). This follicle was identified on Day 3, reached a size of $16 \mathrm{~mm}$ on Day 7, reduced in diameter on Days 8 and 9, and then began a period of siow growth that finished when the follicle reached maximum diameter of $20 \mathrm{~mm}$ on Day 20 (1 day after oestrus; Fig. 2c). Careful examination of the ovaries confirmed that this was the same dominant follicle throughout the oestrous cycle.

\section{Data from cows}

The ultrasound data indicated that Cow 168 had 2 and Cow 141 had 3 dominant follicles during the oestrous cycle. The relationships between the growth of these follicles and progesterone concentrations in blood are presented in Fig. 3.

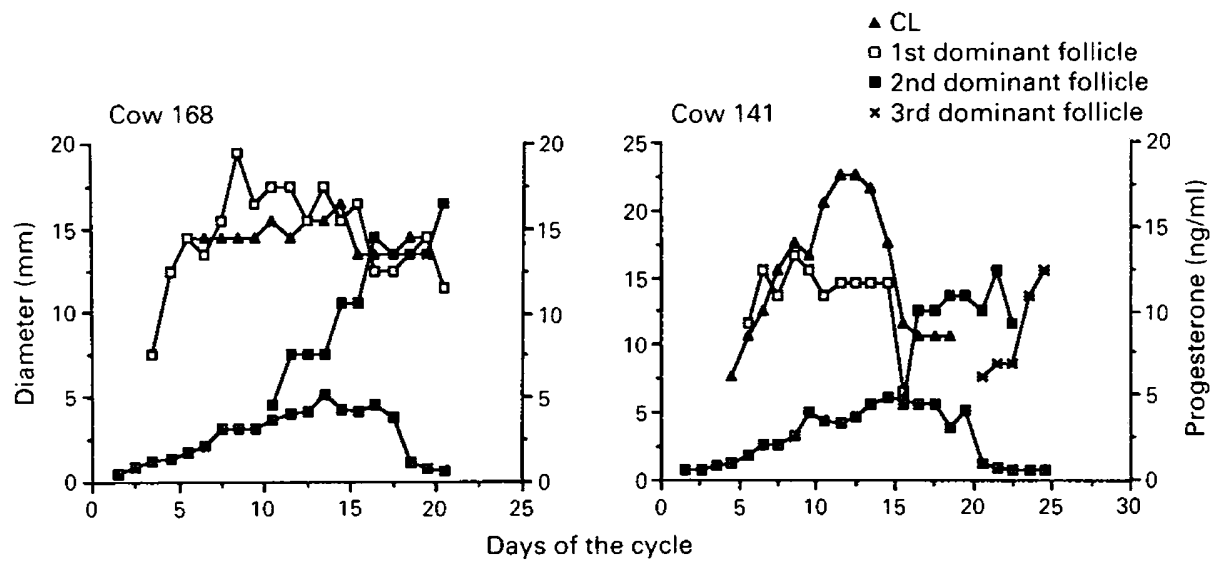

Fig. 3. Growth pattern of the dominant follicles and progesterone concentrations during the oestrous cycles of 2 cows.

\section{Discussion}

The results of this study indicate that most oestrous cycles in beef heifers are characterized by growth of 3 dominant follicles. This finding of sequential growth of 3 dominant follicles may help to explain the findings of previous workers describing ovarian follicular dynamics in cattle using 'nethods other than ultrasound (Rajakoski, 1960; Donaldson \& Hansel, 1968; Matton et al., 1981; eland \& Roche, 1982). In fact, the observation that the first 'morphologically' dominant follicle " ached maximum size by Day 6 agrees with the reports of Matton et al. (1981), Ireland \& Roche (982) and Pierson \& Ginther (1986), who also found dominant follicles at this stage of the cycle. 
Heifer 872
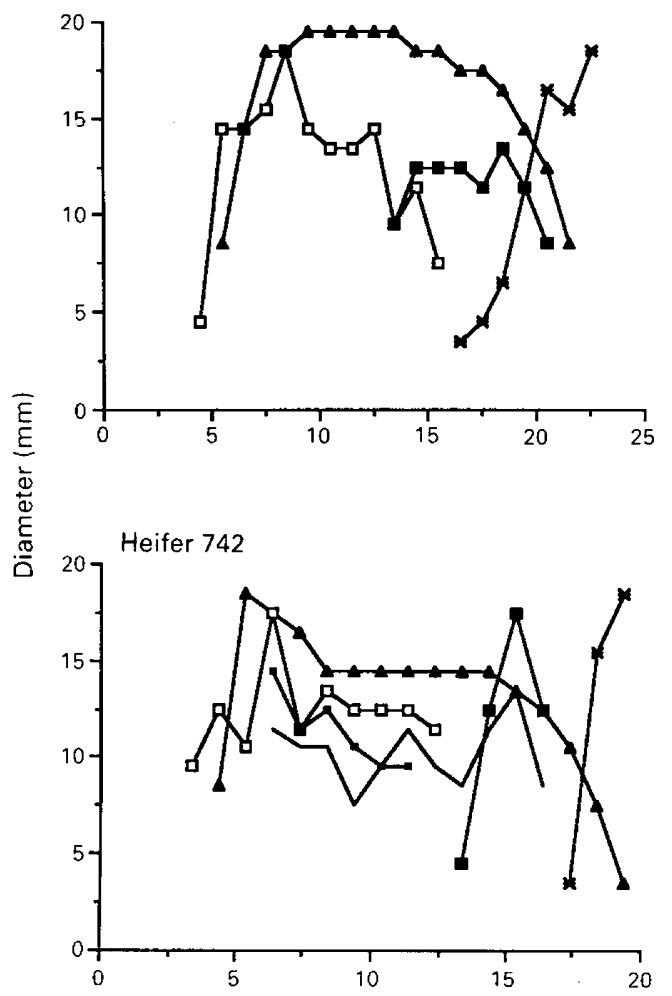

Heifer 752

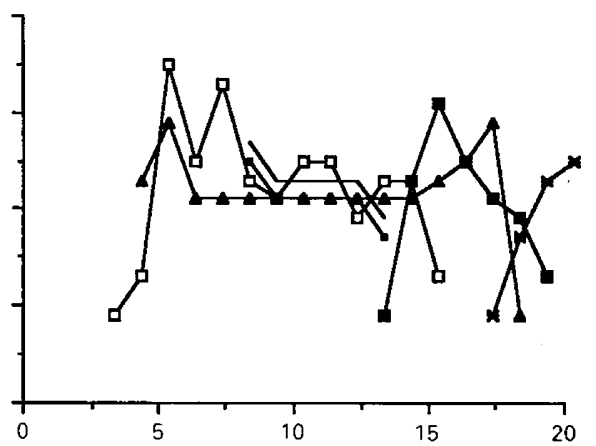

Heifer 722

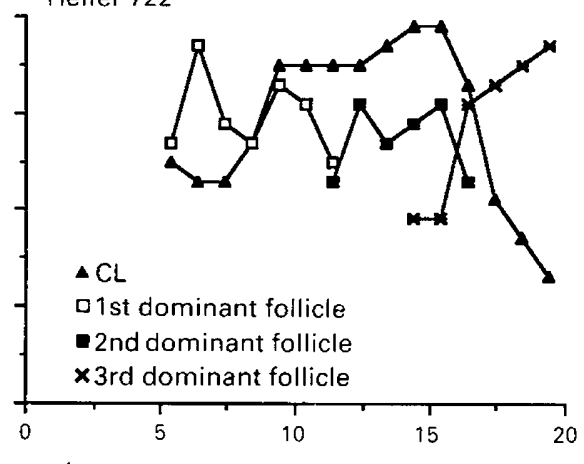

Days of the cycle

Fig. 4. Growth pattern of the dominant follicle in individual heifers during the oestrous cycle as determined by daily ultrasound examination.

The observation that a number of 'first' dominant follicles have a second period of growth during the period of 'stability' and $20 \%$ of these follicles only reached maximum size on Day 9 or 10 could explain the results of Henricks et al. (1972) who found a peak in the concentrations of oestradiol on Day 9 of the cycle, if it is assumed that peripheral blood levels of oestradiol reflect presence of oestrogen-active follicles. Ireland \& Roche (1982) did not exclude the possibility that some follicles, which were considered to be oestrogen-inactive on Days 4-7, could become oestrogen active on Days 8 or 9 . The significantly longer period of detection of the first dominant follicle suggests that it can suppress the growth of other follicles during its period of dominance. The mechanism by which the dominant follicle can continue to grow in an environment unfavourable for growth of secondary follicles, within the same or contralateral ovary, is not clear (Goodman \& Hodgen, 1983).

The second dominant follicle, in cycles with 2 or 3 dominant follicles, had a similar growth pattern until Day 15 or 16, at which time both kinds of follicles (ovulatory and non-ovulatory) were comparable in size. However, the ovulatory follicle continued to grow while the non-ovulatory follicle decreased in size and eventually regressed, due to atresia. Finally, the 3rd dominant follicle went through an initial slow but variable period of growth from Day 10 to 16 , while it was under the influence of the 2 nd dominant follicle. Following the decrease in size of the 2 nd dominant follicle, the growth pattern of the 3 rd dominant follicle was consistent during the final 2-3 days before ovulation; the rates of growth at this time were similar to the final growth phase of the 2 nd dominant follicle, when it was the ovulatory one. Although the number of cycles with 2 dominant 
follicles was small, the results suggest that, due to the slower growth rate and longer duration of detection of the first dominant follicle in these cycles, they exhibited dominance for a longer period than the first dominant follicle in heifers with 3 such follicles during the cycle. That specific dominant follicles can exhibit variable periods of dominance is further substantiated by the one cycle when only a single dominant follicle was present throughout.

Parameters related to temporal measurements, e.g. day of maximum diameter or day of maximum size, showed low variability, in contrast to the greater variability for parameters related to dynamic processes of follicular development, e.g. duration and rates of follicular growth and atresia. For each dominant follicle, similar maximum sizes were reached at equivalent stages of the cycles, even though the rates of growth were different. This implies a variable duration of heterogeneous growth during the cycle, which could explain the difficulties in identifying the preovulatory follicle on a specific day at fixed times of the cycle, using the size of the follicle as the method of identifying the putative ovulatory follicle (Dufour et al., 1972).

Although this work involved the study of follicular dynamics on a morphological basis only, the results suggest that follicular growth is a dynamic process which is under both local and systemic control. Thus, the physical appearance of the follicle, as determined by ultrasonography, is not a reliable indicator of the physiological state of the follicle. In addition, the fact that follicular growth occurred at a faster rate for the $1 \mathrm{st}$ and $3 \mathrm{rd}$ dominant follicles in the last part of their growth phase suggests that the progesterone-dominant luteal phase slows down follicular growth, due presumably to its negative feedback effect on gonadotrophins.

The pattern of follicular growth during the first half of the cycle (between Days 1 and 12), which is characterized by the presence of the first dominant follicle, is clear. The pattern of growth during the second half (from Days 10-12 to the next oestrus) is characterized by new follicles that, after a variable rate of growth, attain 'morphological' dominance and, depending on when the corpus luteum regresses, can either become atretic or ovulate. In the case of the 2 nd dominant follicle which became atretic, a new dominant follicle was detected which eventually, in most cases, ovulated. However, we have observed a different follicular pattern in 1 heifer (unpublished observations) in which 3 sequentially different dominant follicles were observed between Days 17 and 22 . From the results of this study, it is difficult to characterize the pattern of ovarian follicular development during the oestrous cycle by 'waves' (Rajakoski, 1960). Probably, and in agreement with Donaldson \& Hansel (1968), it is more accurate to describe follicular activity as a continuous process of growth and atresia of dominant follicles.

However, between Days 7 and 10 (coincident with the phase of dominance of the first follicle) no growth of new follicles was noted in any heifer, and so the growth of new follicles occurred before or after this period and, from this point of view, two 'waves' of follicular development were consistently obtained, which is in agreement with Rajakoski (1960). If only the large dominant follicle was considered, the results are in agreement with Matton et al. (1981), because 3 periods of growth of large follicles were identified in the majority of cycles. These results suggest that the most difficult time to stimulate follicular growth is at mid cycle, and this observation may have relevance to superovulatory treatments initiated at this time.

In conclusion, follicular dynamics during the oestrous cycle of the majority of heifers was characterized by the growth of 2 or 3 dominant follicles, that, after variable patterns of growth, reached maximum sizes at comparable stages of the oestrous cycle. In addition, preovulatory follicles were larger than non-ovulatory follicles, and during mid-cycle the processes of growth and atresia of follicles were slower than at the beginning or end of the cycle. We therefore suggest that basal concentrations of gonadotrophins are sufficient to stimulate the growth of follicles throughout the oestrous cycle. However, the development of the dominant follicle suppresses further growth of smaller follicles, in both ovaries, by an as yet unknown mechanism. Once regression of the CL occurs, the dominant follicle present, under the influence of increased frequency of loweramplitude LH pulses, begins the preovulatory growth phase, resulting in increased androgen and subsequent oestrogen production. This increased oestrogen results in an LH/FSH surge, which 
is responsible for ovulation. Thus, concentrations of $\mathrm{LH}$ and FSH during the cycle maintain continuous growth of follicles, and the increased LH values during the follicular phase are responsible for stimulating the preovulatory steroidogenic changes resulting in ovulation. This hypothesis on regulation of follicular growth is currently being tested in ongoing experiments in cattle.

We thank Professor J. Hannan for use of the ultrasound machine; Mrs M. R. Mattiacci and the Department of Statistics, U.C.D., for help in analysing the data; and the staff at Lyons Estate for care of the animals.

\section{References}

Anderson, T.W. (1958) An Introduction to Multivariate Statistical Analysis. John Wiley \& Sons, New York.

Donaldson, L.E. \& Hansel, W. (1968) Cystic corpora lutea and normal and cystic graafian follicles in the cow. Aust. vet. J. 44, 304-308.

Dieleman, S.J. \& Schoenmaker, H.J.N. (1979) Radioimmunoassays to determine the presence of progesterone and estrone in the starfish Asterias rubens. Gen. comp. Endocrinol. 39, 534-542.

Dufour, J., Whitmore, H.L., Ginther, O.J. \& Casida, L.E. (1972) Identification of the ovulating follicle by its size on different days of the estrous cycle in heifers. $J$. Anim. Sci. 34, 85-87.

Gill, J.L. (1978) Design and Analysis of Experiments in the Animal and Medical Sciences, Vol. 2. Iowa State University Press, Ames.

Goodman, A.C. \& Hodgen, G.D. (1983) The ovarian triad of the primate menstrual cycle. Recent Progr. Horm. Res. 39, 1-73.

Henricks, D.M., Dickey, J.F., Hill, J.R. \& Johnston, W.E. (1972) Plasma estrogen and progesterone levels after mating and during late pregnancy and postpartum in cows. Endocrinology 90, 1336-1342.

Ireland, J.J. \& Roche, J.F. (1982) Development of antral follicles in cattle after prostaglandin-induced luteolysis: changes in serum hormones, steroids in follicular fluid, and gonadotropin receptors. Endocrinology 111, 2077-2086.

Ireland, J.J. \& Roche, J.F. (1983) Development of nonovulatory antral follicles in heifers: changes in steroids in follicular fluid and receptors for gonadotropins. Endocrinology 112, 150-156.

Ireland, J.J. \& Roche, J.F. (1987) Hypotheses regarding development of dominant follicles during a bovine estrous cycle. In Follicular Growth and Ovulation Rate in Farm Animals, pp. 1-18. Eds J. F. Roche \& D. O'Callaghan. Martinus Nijhoff, The Hague.

Matton, P., Adelakoun, V., Couture, Y. \& Dufour, J.J. (1981) Growth and replacement of the bovine ovarian follicles during the estrous cycle. J. Anim. Sci. 52, 813-820.

Pierson, R.A. \& Ginther, O.J. (1984) Ultrasonography of the bovine ovary. Theriogenology 21, 495-504.

Pierson, R.A. \& Ginther, O.J. (1986) Ovarian follicular populations during early pregnancy in heifers. Theriogenology 26, 649-659.

Quirk, S.M., Hickey, G.J. \& Fortune, J.E. (1986) Growth and regression of ovarian follicles during the follicular phase of the oestrous cycle in heifers undergoing spontaneous and PGF-2 $\alpha$-induced luteolysis. J. Reprod. Fert. 77, 211-219.

Rajakoski, E. (1960) The ovarian follicular system in sexually mature heifers with special reference to seasonal, cyclical and left-right variations. Acta endocr., Copenh., Suppl. 52, 1-68.

S.A.S. (1986) Users Guide: Statistics. Statistical Analysis System Institute, Inc., Cary, N.C.

Snedecor, G.W. \& Cochran, W.G. (1980) Statistical Methods, 7th edn. Iowa State University Press, Ames.

Received 16 October 1987 